\title{
Bone marrow -derived mesenchymal stem cells inhibiting CD8+ T cell immune responses via PD-1/PD-L1 pathway in multiple myeloma
}

\author{
zhaoyun liu ${ }^{1}, \mathrm{Fu} \mathrm{Mi}{ }^{1}$, Mei Han ${ }^{1}$, Mengyue Tian ${ }^{1}$, Ling Deng ${ }^{1}$, Nanhao Meng ${ }^{1}$, Jingyi Luo ${ }^{1}$, \\ and Rong $\mathrm{Fu}^{2}$ \\ ${ }^{1}$ Tianjin Medical University General Hospital \\ ${ }^{2}$ Tianjin medical university general hospital
}

May 20, 2020

\begin{abstract}
High expression of the inhibitory receptor programmed death ligand 1 (PD-L1) on the surface of tumor cells have been found play a key role in tumor immune evasion in several human malignancies. However, the expression of PD-L1 on bone marrow mesenchymal stem cells (BMSCs) and whether the PD-1/PD-L1 axis is involved in the BMSCs versus T cell immune response in Multiple Myeloma (MM) remain poorly defined. In this study, we explored the expression of PD-L1 on BMSCs from MM patients and the role of PD-1/PD-L1 pathway in BMSCs-mediated regulation of CD8+T cells. We observed that the expression of PD-L1 on BMSCs was significantly higher in NDMM group, compared with the NC group $(18.81 \pm 1.61 \%$ vs. $2.78 \pm 0.70 \%$; $\mathrm{P}<0.001)$. Furthermore, the expression of PD-1 on CD8+ T cells in NDMM group was significantly higher than that in control group $(43.22 \pm 2.98 \%$ vs. $20.71 \pm 1.08 \%$; $<0.001)$. However, there was no significant difference in PD-1 expression of CD4+ $\mathrm{T}$ cells and NK cells between NDMM group and NC group. Additionally, the co-culture assays revealed that BMSCs significantly promoted CD8+ T cell apoptosis and suppressed CD8+ T cell function. However, PD-L1 inhibitor effectively reversed BMSCsmediated suppression in CD8 $+\mathrm{T}$ cells. We also found that the combination of PD-L1 inhibitor and pomalidomide can further enhance the killing effect of CD8 $+\mathrm{T}$ cells on MM cells. In summary, our findings demonstrated that BMSCs may induce apoptosis and functional imbalance of CD8+ T cells via PD-1/PD-L1 pathway and promote the immunity escape of MM.
\end{abstract}

\section{Hosted file}

manuscript.doc available at https://authorea.com/users/323220/articles/452026-bone-marrowderived-mesenchymal-stem-cells-inhibiting-cd8-t-cell-immune-responses-via-pd-1-pd-11pathway-in-multiple-myeloma 


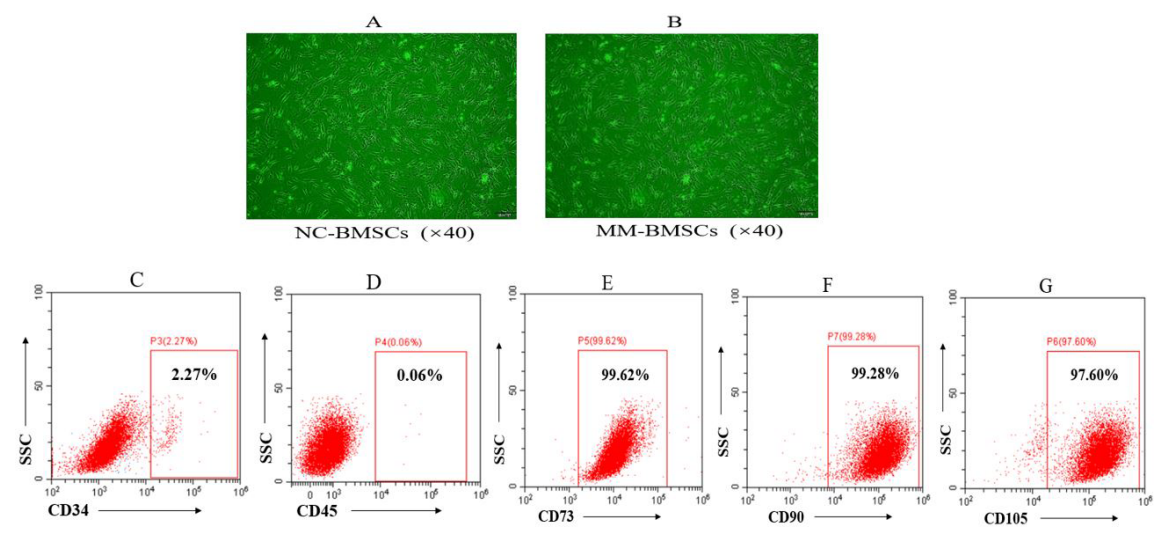

Figure 1: This is a caption
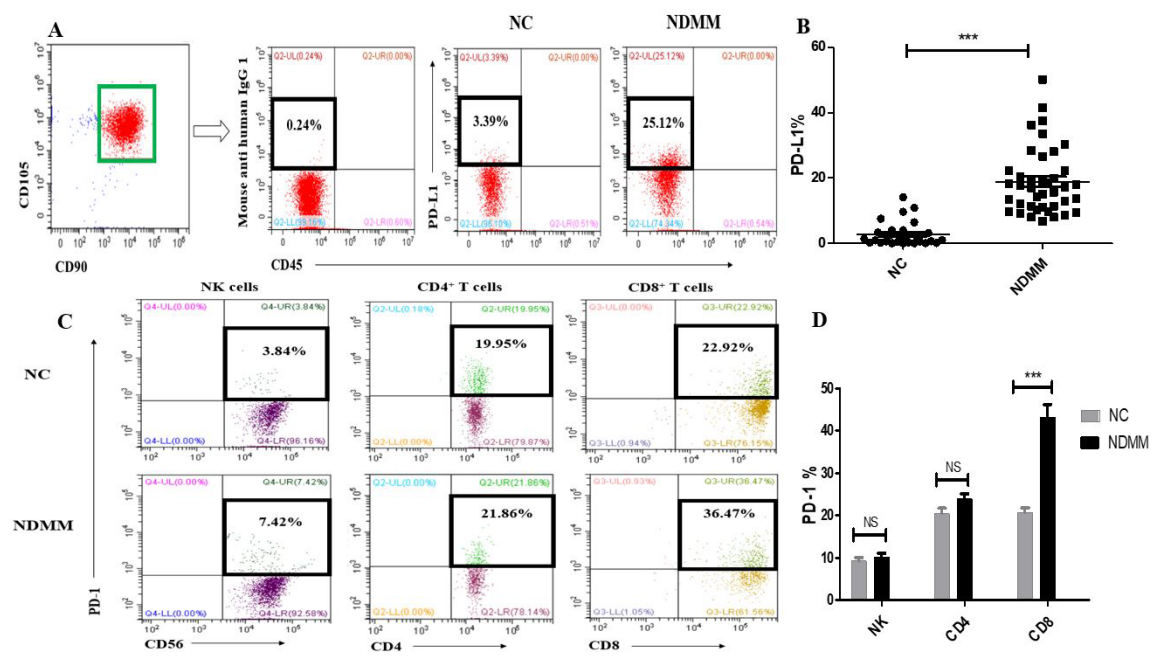

Figure 2: This is a caption 

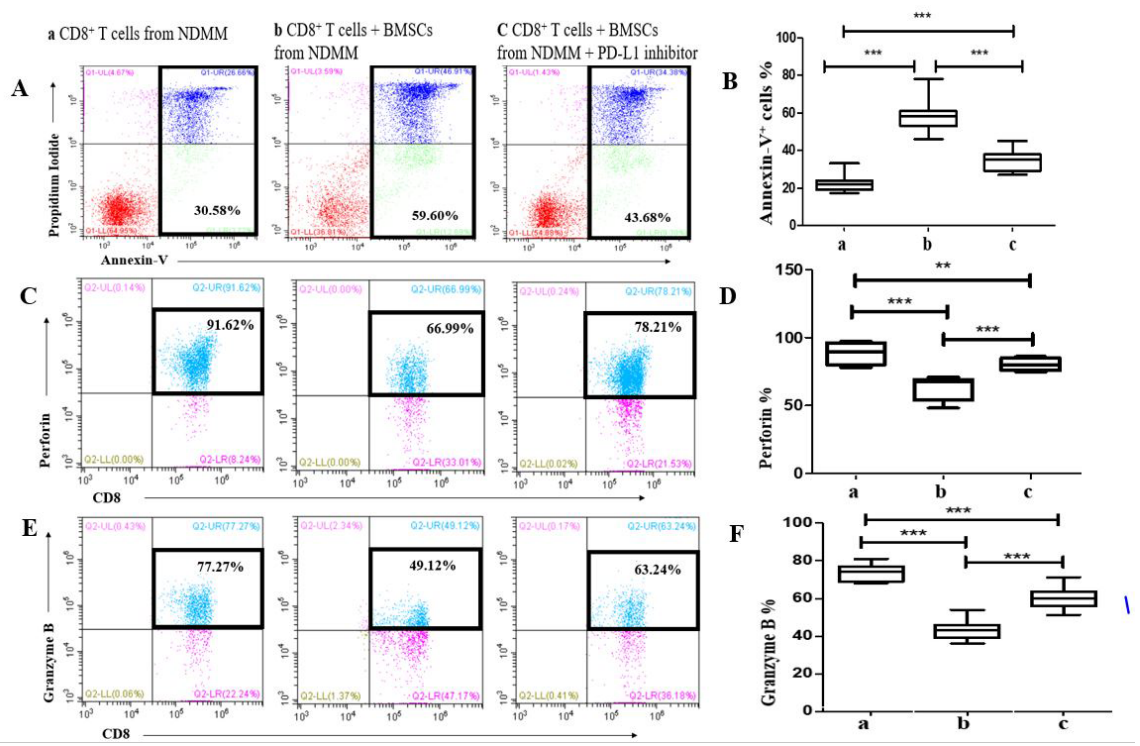

Figure 3: This is a caption

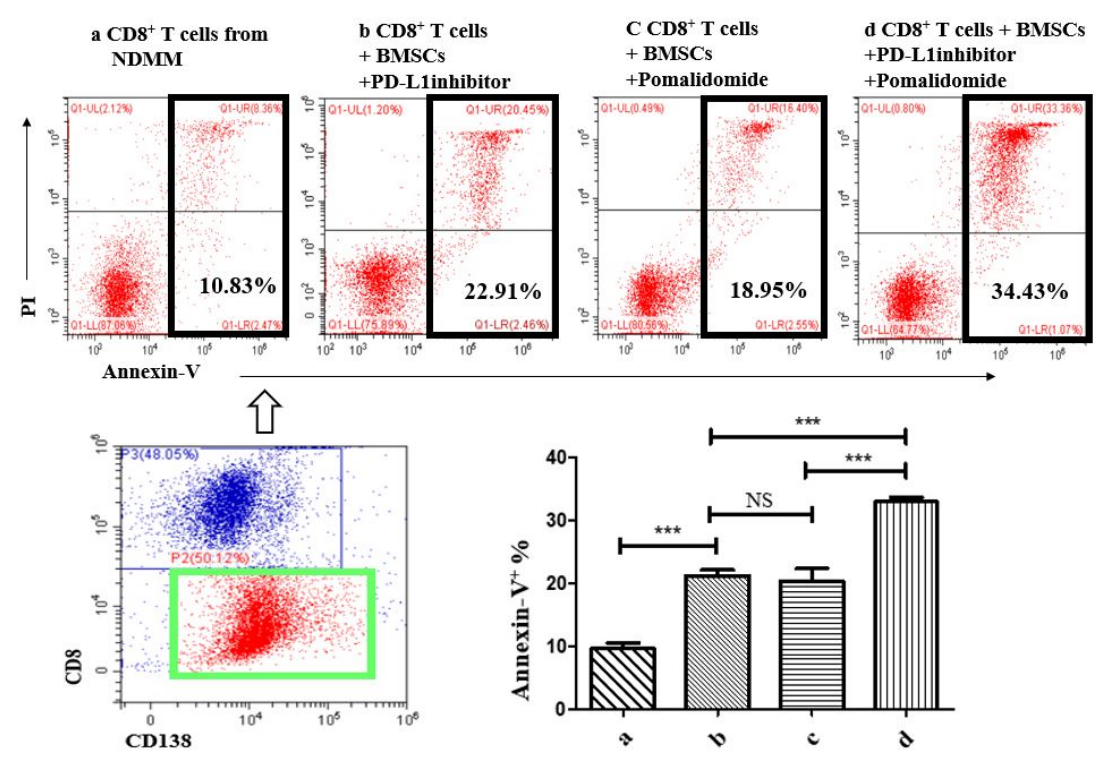

Figure 4: This is a caption

\section{Hosted file}

Table 1 Baseline characteristics of patients with NDMM1.doc available at https://authorea. com/users/323220/articles/452026-bone-marrow-derived-mesenchymal-stem-cells-inhibitingcd8-t-cell-immune-responses-via-pd-1-pd-l1-pathway-in-multiple-myeloma 